\title{
EXPERIMENTAL VALIDATION OF THE MAXWELL-STEFAN THEORY FOR THE DESCRIPTION OF LIQUID-SIDE MASS TRANSFER IN A BINARY MIXTURE - AMMONIA ABSORPTION IN WATER USING A STIRRED CELL
}

\author{
M.J.W. FRANK, J.A.M. KUIPERS AND W.P.M. VAN SWAAIJ
}

\author{
Department of Chemical Engineering, Twente University, P.O. Box 217, 7500 AE Enschede, The Netherlands
}

\begin{abstract}
The main goal of this paper is to demonstrate the validity of the Maxwell-Stefan theory for the description of liquid phase mass transport processes in a binary mixture. To critically test this theory absorption experiments of ammonia in water were conducted in a stirred cell. The flux model developed by Frank et al. (1995a) has been extended to a dynamic reactor model taking thermodynamic non-idealities and concentration and temperature dependent physical parameters into account . Calibration of the stirred cell was achieved on basis of carbon dioxide absorption experiments in water. By using the Maxwell-Stefan flux expressions instead of Fick's first law, and therefore accounting for the convective transport contributions, the deviation between theory and experiment reduces from $20-30 \%$ to $5 \cdot 10 \%$.
\end{abstract}

\section{INTRODUCTION}

Mass transfer between a gas and a liquid plays an important role in many industrial processes. Examples are distillation, reactive distillation and various ab-and desorption processes. Usually the mass transport is described with Fick's first law, which postulates a linear dependence of the flux of a certain component with respect to its concentration gradient. In case of e.g. distillation and absorption of highly soluble gases sonvective transport contributions (i.e. drift) play an important role. This additional transport mechanism can lead to situations where fluxes of components are directed against their concentration gradients or situations in which an apparent enhancement of mass transfer occurs. The Maxwell-Stefan theory for mass transport can describe these phenomena on a more correct and fundamental basis. Within the framework of this theory the sum of all driving forces is set equal to the sum of all resistance forces. The interaction between the components is represented with binary diffusion coefficients. Frank et al. (1995a,1995b) developed a general applicable model, based on the Maxwell-Stefan theory, which can predict mass and heat transfer fluxes through a vapour/gas-liquid interface in case a reversible chemical reaction with associated heat effect takes place in the liquid phase. In these theoretical studies it was shown that in case of absorption of a pure, highly soluble gas, the Maxwell-Stefan theory should be used and more importantly that heat effects, due to heat of dissolution, may affect the absorption rate considerably.

In literature it has already been shown that the Maxwell-Stefan theory constitutes an excellent theoretical framework to predict, qualitatively and quantitatively, experimental data for various gas phase mass transport processes (see e.g. Taylor and Krishna (1993) with experimental data of Duncan (1962), Arnold (1967), Carty and Schrodt (1975)). In case of liquid phase mass transport processes the quantitative validations of the MStheory are relatively scarce and less evident, partly due to the fact that binary diffusion coefficients are composition dependent (see e.g. Taylor and Krishna (1993) with experimental data of Krishna et al. (1985), Krishnamurthy and Taylor (1985) and Vogelpohl (1979)).

The main goal of this paper is to demonstrate the validity of the Maxwell-Stefan theory for the description of liquid phase mass transport processes in a binary mixture. In this case the MS-theory simplifies to Fick's first law with superimposed drift. Therefore absorption experiments of carbon dioxide in water and ammonia in water were performed using a stirred cell where the experimental data were compared with theoretically predicted absorption fluxes using a dynamic reactor model.

\section{THEORY}

The detailed description of the gas - liquid flux model is given in Frank et al. (1995a) and will not be repeated here. This model can predict mass and heat transfer fluxes through a vapour/gas-liquid interface in case a reversible chemical reaction with associated heat effect takes place in the liquid phase. It is based on the film model where the Maxwell-Stefan theory has been used to describe the mass transport. The original model, which assumes a thermodynamic ideal system, has been extended to account for the thermodynamic non-idealities by using the general Maxwell-Stefan equation (see Table 1) where the physical parameters are taken temperature and composition dependent. Furthermore the flux model has been embedded into a dynamic reactor model taking 
convective transport in the bulk of both phases into account (see Figure 1). The model equations as well as the input data are shown in Table 1.

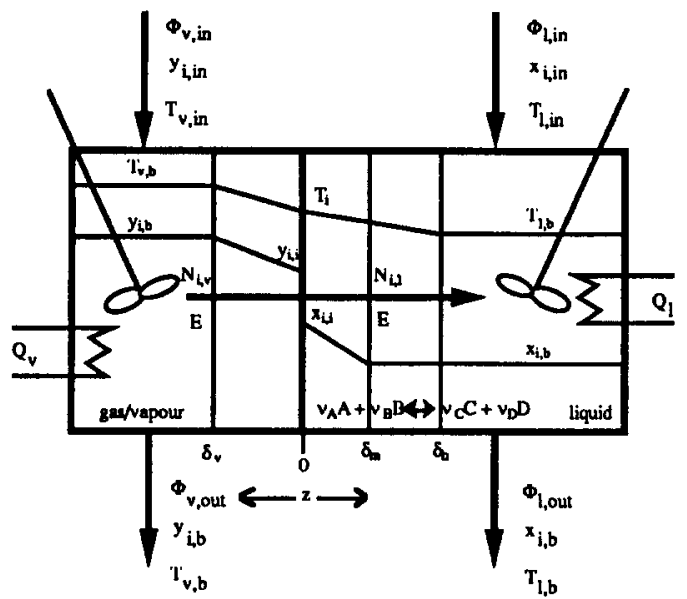

Figure 1 Schematic representation of the reactor model.

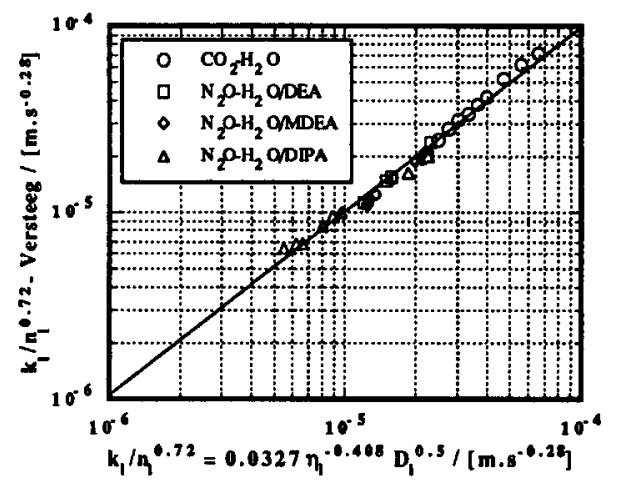

Figure 2 Correlation of mass transfer data of Versteeg (1987).

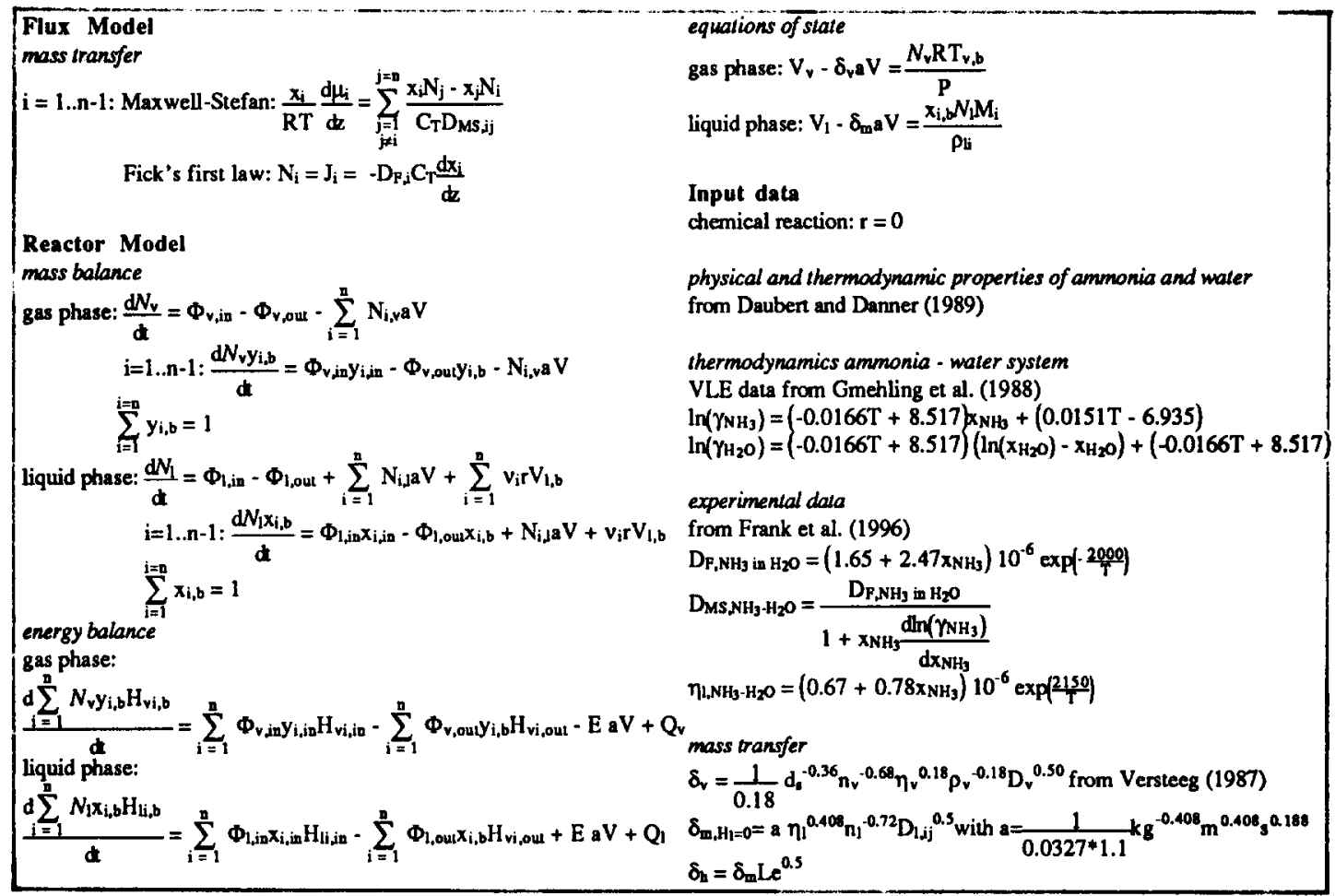

Table 1 Model equations and input data for dynamic reactor model.

Three input parameters are unknown and depend on the reactor which is used: the film thickness in the gas phase $\delta_{v}$ and the film thicknesses $\delta_{m}$ and $\delta_{h}$ for respectively mass and heat transfer in the liquid phase. As only experiments are carried out with pure gases and gas phase resistance is negligible an exact value for $\delta_{\mathrm{v}}$ is not required. The film thickness for heat transfer $\delta_{h}$ can be calculated from the film thickness for mass transfer $\delta_{m}$ and the Lewis number if an assumption concerning the nature of the transport processes is made. The film thickness for mass transfer has to be known as function of a number of parameters such as the diffusion coefficient, liquid viscosity and reactor geometry. Versteeg (1987), who has used almost the same stirred cell for his absorption experiments, has developed an empirical correlation for the Sherwood number. A critical examination of this Sherwood correlation reveals that some parameters appearing in the dimensionless groups have not actually been varied such as the stirrer diameter $d_{s}$ and liquid density $\rho_{l}$. Furthermore, the diffusion coefficient and the liquid viscosity have not been changed independently and since their product was almost 
constant, the dependence of the mass transfer coefficient on the diffusion coefficient cannot be determined accurately. Therefore the data of Versteeg (1987), obtained for the $\mathrm{CO}_{2}-\mathrm{H}_{2} \mathrm{O}, \mathrm{N}_{2} \mathrm{O}-\mathrm{H}_{2} \mathrm{O} / \mathrm{DEA}, \mathrm{N}_{2} \mathrm{O}-\mathrm{H}_{2} \mathrm{O} / \mathrm{MDEA}$ and $\mathrm{N}_{2} \mathrm{O}-\mathrm{H}_{2} \mathrm{O} / \mathrm{DIPA}$ systems, have been reinterpreted in this study where the following expression was used as the starting point:

$$
\frac{\mathrm{k}_{1}}{\mathrm{n}_{1}{ }^{0.72}}=\mathrm{a} \eta_{1}^{\mathrm{b}} \mathrm{D}_{1}^{\mathrm{c}}
$$

The constant $c$ was given respectively values of $0,0.5$ (penetration theory) or 1 (film theory). The best fit was obtained with $c=0.5$, producing an average deviation of $5.9 \%$ with a standard deviation of $3.6 \%$. Figure 2 shows a parity plot of the experimental data points of Versteeg and the best fit according to eq. (1) obtained in this study. The film thickness for mass transfer $\delta_{m}$ can be calculated from eq.(1) according to

$$
\delta_{m}=D_{1} / k_{1}
$$

As $c=0.5$ indicates a penetration type of mass transfer, the film thickness for heat transfer is given by:

$$
\frac{\delta_{h}}{\delta_{m}}=L e^{0.5}
$$

Evaluation of viscosity, diffusion coefficient and Lewis number, data which are required for calculating $\delta_{m}$ and $\delta_{h}$, involves an iterative process since these quantities have been obtained by averaging their respective values at the gas-liquid interface and the liquid phase bulk.

\section{EXPERIMENTAL SET-UP}

A flow scheme of the experimental set-up is given in Figure 3. The absorption experiments were carried out in a thermostatted double walled stirred cell of glass with an internal diameter of $94.4 \mathrm{~mm}$ and a height of 208 $\mathrm{mm}$. Four baffles are present in the liquid phase to obtain a flat liquid surface. The gas and liquid phase can be stirred independently. The liquid phase stirrer consists of 3 pairs of stirrer blades with a blade height of $10 \mathrm{~mm}$ and a total diameter of $70 \mathrm{~mm}$, its speed can be varied between 0.2 and $1.5 \mathrm{~s}^{-1}$. The gas phase stirrer consists of 5 pairs of stirrer blades and has a standard stirrer speed of $4 \mathrm{~s}^{-1}$. Thermocouples have been positioned at 4 axial positions to measure the temperature of both phases at several radial and two axial positions. The stirred cell is equipped with a pressure transducer mounted in its top-side wall and is operated with continuous throughflow of both phases. This mode of operation offers the opportunity to measure under steady state conditions and gives accurate results.

The liquid is fed to the reactor from a small storage vessel located at an elevation of $4 \mathrm{~m}$ resulting in a constant liquid head to ensure a constant liquid flow rate. Before the liquid enters the stirred cell it passes a rotameter and a heating coil to obtain the desired reactor temperature. The liquid level in the stirred cell is kept constant manually by controlling the outlet liquid flow rate with a rotameter. Before the liquid enters this rotameter it is cooled down to room temperature. In case of $\mathrm{CO}_{2}$ absorption in water the liquid phase reactor effluent is sent directly to the drain, whereas in case of $\mathrm{NH}_{3}$ absorption the liquid phase waste stream is collected in a storage vessel. The liquid phase volume is $550 \mathrm{ml}$ and the liquid flow rate can be varied between 0.05 and 3 $\mathrm{ml} / \mathrm{s}$.

The gas inlet section consists of 2 mass flow controllers to obtain constant flow rates of carbon dioxide or ammonia. The flow ranges are respectively 100 and $10000 \mathrm{nCC} \mathrm{N} /$ min. Before the gas enters the stirred cell it passes a heating coil to obtain the desired inlet temperature. The outlet gas flow rate is measured with 2 mass flow meters with maximum flow rates of 100 and $1000 \mathrm{nCC} \mathrm{N} / \mathrm{min}$. All relevant pieces of our equipment were kept at a constant temperature of $50^{\circ} \mathrm{C}$ to prevent condensation of water. In case of absorption of $\mathrm{CO}_{2}$ the gas phase waste stream was vented, whereas in case of absorption of $\mathrm{NH}_{3}$ the gas phase waste stream was fed to a scrubber.

Absorption fluxes were measured by setting the flow rates of both phases, the temperature of the thermostatted bath, the liquid height and monitoring the outlet flow rate of the gas phase. Corrections were made for the presence of water in the outflowing gas, using the assumption that the gas phase is saturated.

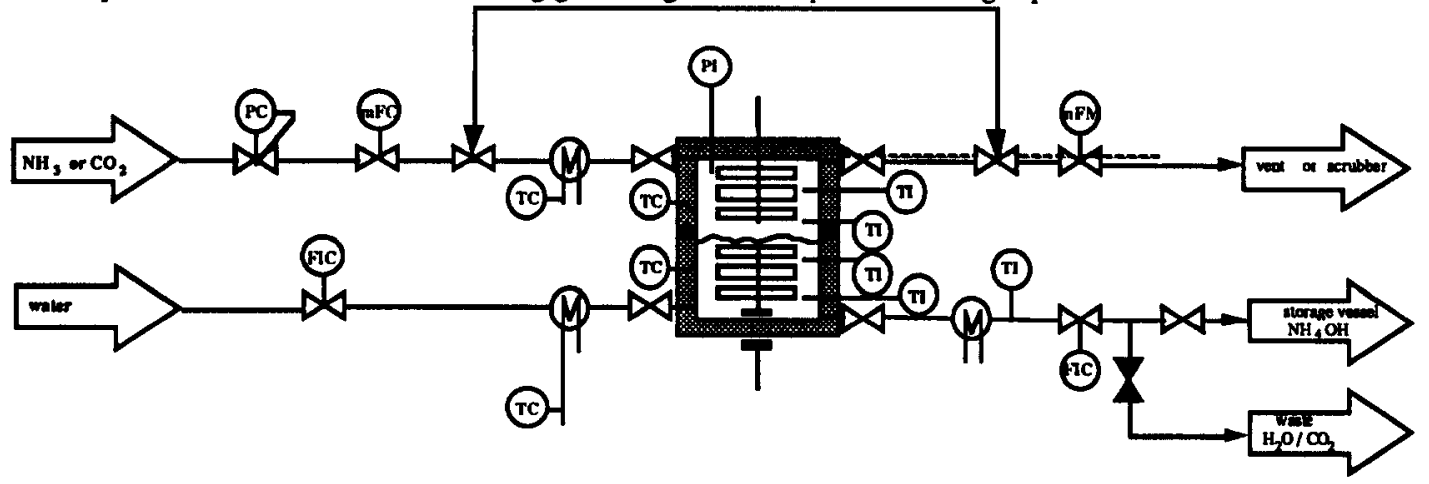

Figure 3 Flow scheme of the experimental set-up. 


\section{RESULTS AND DISCUSSION}

$\mathrm{CO}_{2} \cdot \mathrm{H}_{2} \mathrm{O}$

Like almost all gases $\mathrm{CO}_{2}$ has a low solubility in water and as a consequence the Maxwell-Stefan flux expression reduces to the well-known Fick's first law. Furthermore, thermodynamic non-idealities and heat effects are negligible and the mass transfer coefficient $k_{1}$ can directly be calculated from the experimentally determined absorption fluxes. Absorption experiments of $\mathrm{CO}_{2}$ in water were conducted to investigate whether the mass transfer coefficients can indeed be represented by correlation (1) with values for the constants $\mathrm{a}, \mathrm{b}$ and $\mathrm{c}$ as given in Figure 2. Since the dimensions and geometry of our cell only slightly differ from those of the stirred cell used by Versteeg (1987) it is expected that the same correlation applies in this case with a possible minor modification of the empirical constant a. Furthermore, measurements were carried out to investigate the correctness of our experimental approach which differs from the one adopted by Versteeg (1987).

Experiments revealed that the measured $\mathrm{CO}_{2}$ absorption flux was unaffected by the flow rate of both phases and stirrer speed in the gas phase. However, contrary to Versteeg's finding, an influence of the liquid height on the $\mathrm{CO}_{2}$ absorption flux was found, as depicted in Figure 4. In this figure the ratio of the experimental and calculated (from correlation (1)) mass transfer coefficient has been plotted as function of liquid height $\mathrm{H}_{\mathrm{l}}$, where $\mathrm{H}_{1}=0$ and $\mathrm{H}_{1}=-1 \mathrm{~cm}$ represent the situations where the gas-liquid interface coincides with respectively the top and the bottom of the upper stirrer blades. Note that a maximum occurs at $\mathrm{H}_{1}=0 \mathrm{~cm}$. The experimental mass transfer coefficients equal their calculated counterparts in case the liquid interface is positioned half way the stirrer blade or a few mm's above the stirrer blade. In case the liquid surface is positioned in the neighbourhood of the lower stirrer blades, a similar profile and practically identical $k_{1}$ values are found in comparison with the results for the upper stirrer blade. In this study $\mathrm{H}_{1}=0$ has been chosen as the standard situation.

Mass transfer coefficients were determined for various liquid phase stirrer speeds, liquid phase temperatures and liquid flow rates. Figure 5 shows a comparison between our experimental $k_{1}$ data and the $k_{1}$ values obtained from correlation (1). It can be concluded that the average deviation in case of $\mathrm{H}_{1}=0$ is approximately $+10 \%$, which is probably due to the aforementioned phenomenon and slightly different reactor dimensions. To account for the effect of $\mathrm{H}_{1}$ on the mass transfer coefficient the empirical constant a appearing in correlation (1) has been taken as a function of $\mathrm{H}_{1}$. The resulting adapted mass transfer correlation, shown in Table 1, has been used in our theoretical model to calculate the fluxes in case of ammonia absorption in water.

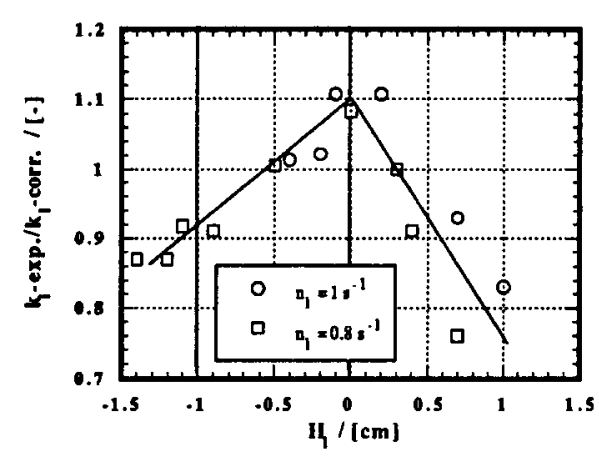

Figure 4 Influence of liquid height on mass transfer coefficient for $\mathrm{CO}_{2}$ absorption in water. $\mathrm{T}=20^{\circ} \mathrm{C}, \mathrm{L}=1 \mathrm{ml} / \mathrm{s}$.

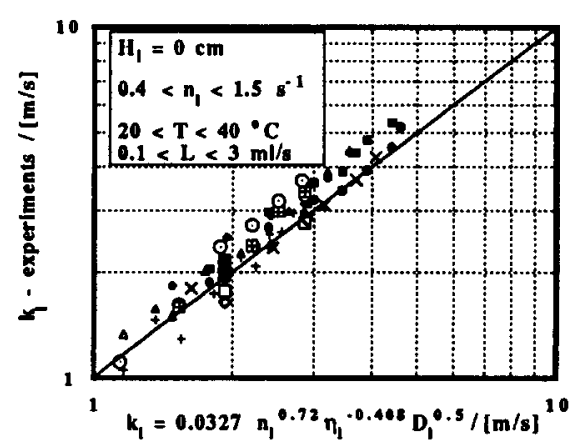

Figure 5 Parity plot of experimental mass transfer coefficients of $\mathrm{CO}_{2}$ absorption in water and mass transfer coefficient correlation.

\section{$\mathrm{NH}_{3}-\mathrm{H}_{2} \mathrm{O}$}

Contrary to other gases, ammonia has a very high solubility in water, despite its non-dissociating character. Due to this high solubility, convective transport will become important and additionally due to high absorption fluxes heat effects will become significant, resulting in temperature profiles near the gas-liquid interface. With this absorption system it is possible to demonstrate that the Maxwell-Stefan theory is required for describing mass transport, i.e. taking convective contributions into account, and additionally that heat effects must be taken into account.

First experiments were conducted to investigate the influence of the liquid height on the absorption flux of ammonia in water. The results are shown in Figure 6 and indicate a similar dependence as was found in case of $\mathrm{CO}_{2}$ absorption. Here also $\mathrm{H}_{1}=0$ was taken as the standard situation. Furthermore it can be seen from Figure 6 that our model predicts the experimentally observed $\mathrm{NH}_{3}$ absorption fluxes very well.

Figure 7 shows a typical graph where the experimental fluxes are plotted as function of liquid stirrer rate. At low stirrer rates unexpected low absorption fluxes are observed, which either may be attributed to incomplete mixing of the liquid bulk or to the fact that the interface, with its higher ammonia concentration, is less dense than the liquid bulk and as a consequence vertical mixing of surface elements is incomplete, causing higher contact times and consequently lower mass transfer coefficients and lower fluxes. However with increasing stirrer 
rates the experimental fluxes approach the predictions obtained from the reactor model provided that the Maxwell-Stefan flux expressions are used and heat effects are taken into account. Typical deviations between theory and experiment range from 5 to $10 \%$. If Fick's first law is used and convective mass transfer is neglected the model systematically underpredicts the experimentally observed absorption fluxes, resulting at high stirrer rates in typical deviations of 20 to $30 \%$. If heat effects are neglected the predicted fluxes are too high, due to the overestimation of $\mathrm{NH}_{3}$ solubility.

Similar effects can be inferred from Figure 8 where the $\mathrm{NH}_{3}$ absorption fluxes are plotted as function of liquid bulk temperature. Note that the experimentally found dependence is predicted very well by the model. In case Fick's first law is used the model systematically underpredicts the observed $\mathrm{NH}_{3}$ absorption fluxes where the deviation slightly increases with decreasing temperature.

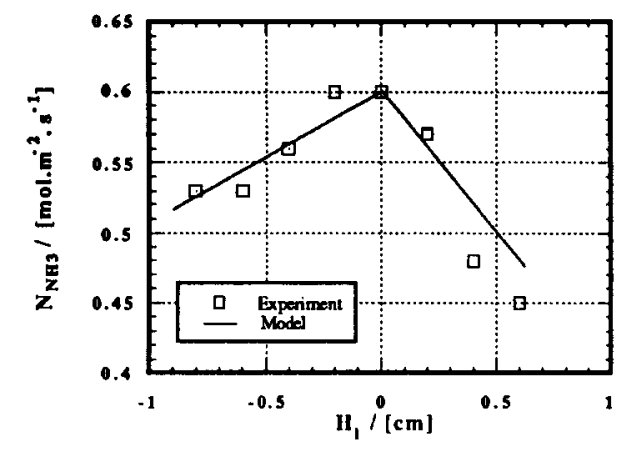

Figure 6 Influence of liquid height on absorption flux of $\mathrm{NH}_{3}$ in water. $\mathrm{T}=25^{\circ} \mathrm{C}, \mathrm{L}=1 \mathrm{ml} / \mathrm{s}, n_{1}=1.2 \mathrm{~s}^{-1}$.

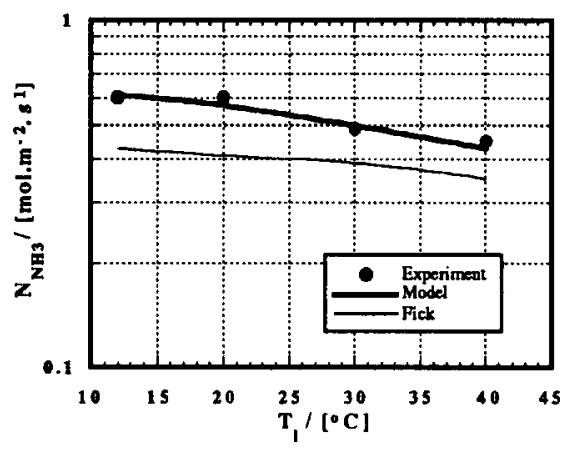

Figure 8 Influence of liquid bulk temperature on absorption flux of $\mathrm{NH}_{3}$ in water. $\mathrm{n}_{1}=1 \mathrm{~s}^{-1}, \mathrm{~L}=1 \mathrm{ml} / \mathrm{s}$.

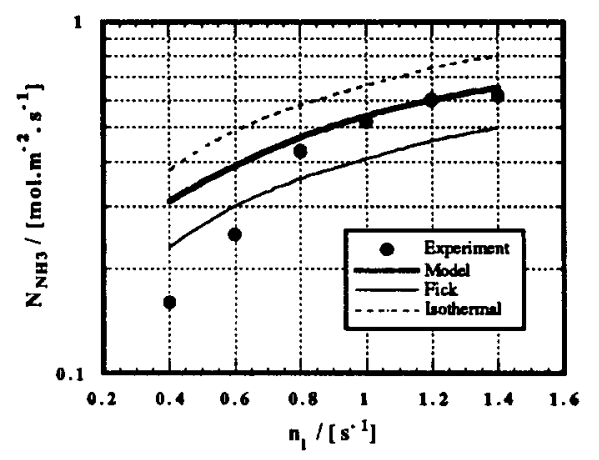

Figure 7 Influence of liquid stirrer rate on absorption flux of $\mathrm{NH}_{3}$ in water. $\mathrm{T}=25^{\circ} \mathrm{C}, \mathrm{L}=1 \mathrm{~m} / \mathrm{s}$.

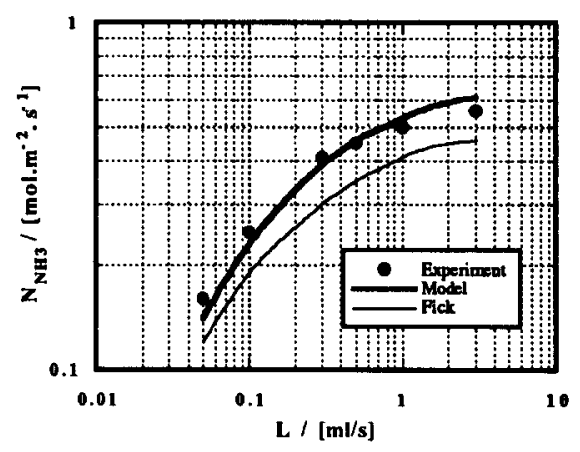

Figure 9 Influence of liquid flow rate on absorption flux of $\mathrm{NH}_{3}$ in water. $\mathrm{T}=25^{\circ} \mathrm{C}, \mathrm{n}_{\mathrm{l}}=1 \mathrm{~s}^{-1}$.

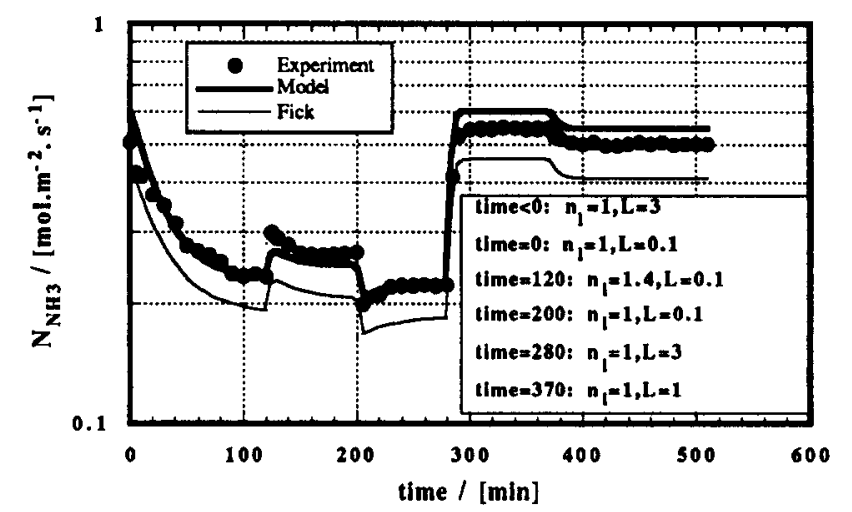

Figure 10 Dynamic response of the absorption flux of $\mathrm{NH}_{3}$ in water with respect to sudden changes in liquid flow rate and liquid stirrer rate. $\mathrm{T}=25^{\circ} \mathrm{C}$. 
At high liquid stirrer rates the well mixed bulk conditions is fulfilled as is evident from Figure 9 since the fluxes are predicted very well for the entire range of liquid flow rates.

Figure 10 shows the dynamic response of the $\mathrm{NH}_{3}$ absorption flux due to sudden in- or decreases of the liquid flow rate or the liquid stirrer rate. It can be seen that the model not only accurately predicts the stationary fluxes well, but also predicts the system dynamics very well.

\section{CONCLUSIONS}

The absorption flux of ammonia in water can be predicted by extrapolation of experimental data of $\mathrm{CO}_{2}$ absorption in water provided that the Maxwell-Stefan theory is used for the description of the mass transfer process and heat effects are taken into account. However, in case of ammonia absorption in water, contrary to the $\mathrm{CO}_{2}-\mathrm{H}_{2} \mathrm{O}$ system, density and viscosity gradients are expected to exist at the gas - liquid interface, phenomena which might be the cause of the unexpected low $\mathrm{NH}_{3}$ absorption flux observed at low liquid stirrer rates.

Acknowledgements - We acknowledge S. Kuipers and W. Leppink for their technical support and A. van der Veen and $\mathrm{E}$. Kool for their contribution to the experimental work. These investigations were supported by the Foundation for Chemical Research in the Netherlands (S.O.N.).

\section{NOTATION}

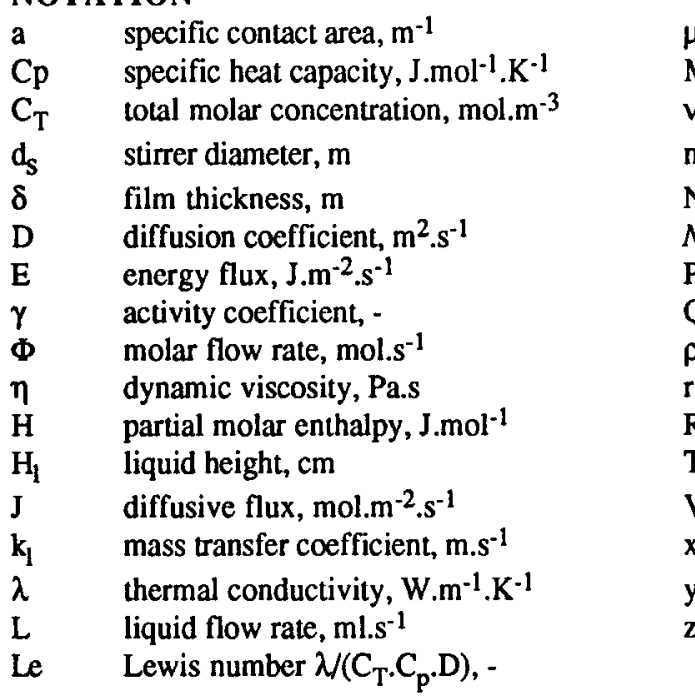

subscripts

$\begin{array}{llll}\text { b } & \text { bulk } & 1 & \text { liquid } \\ \text { F } & \text { Fick } & \mathrm{m} & \text { mass } \\ \text { h } & \text { heat } & \text { MS } & \text { Maxwell-Stefan } \\ \text { i } & \text { interface } & v & \text { vapour }\end{array}$

\section{REFERENCES}

Daubert, T.E. and Danner, R.P., 1989, Physical and thermodynamic properties of pure chemicals: data compilation Taylor and Francis, London, UK.

Frank, M.J.W., Kuipers, J.A.M., Versteeg, G.F. and van Swaaij, W.P.M., 1995a, Modelling of simultaneous mass and heat transfer with chemical reaction using the Maxwell-Stefan theory - I. model development and isothermal study Chem.Engng Sci. 50, 1645-1659.

Frank, M.J.W., Kuipers, J.A.M., Krishna, R., and van Swaaij, W.P.M., 1995b, Modelling of simultaneous mass and heat transfer with chemical reaction using the Maxwell-Stefan theory - II. non-isothermal study Chem.Engng Sci. 50, 1661-1671.

Frank, M.J.W., Kuipers, J.A.M., and van Swaaij, W.P.M., 1996, Diffusion coefficients and viscosities of $\mathrm{CO} 2+\mathrm{H} 2 \mathrm{O}, \mathrm{CO} 2+\mathrm{CH} 3 \mathrm{OH}, \mathrm{NH} 3+\mathrm{H} 2 \mathrm{O}$ and $\mathrm{NH} 3+\mathrm{CH} 3 \mathrm{OH}$ liquid mixtures. J.Chem. Engng Data to be published.

Gmehling, J., Onken, U. and Rarey-Nies, J.R., 1988, Vapor-liquid equilibrium data collection, vol.1 part Ib Chemistry data series, Dechema, Frankfur//Main.

Taylor, R. and Krishna, R., 1993, Multicomponent Mass Transfer Wiley, New York.

Versteeg, G.F., 1987, Mass transfer and chemical reaction kinetics in acid gas treating processes $P h . D$. Thesis, Twente University, Enschede, The Netherlands. 